\title{
IN-SITU TIC PRECIPITATION IN MOLTEN FE-CR-C AND THEIR CHARACTERIZATION
}

\author{
Srinivasa $\mathbf{K}^{1}$, K I Parashivamurthy ${ }^{2}$, Rakshith $\mathbf{N}^{3}$ \\ ${ }^{1}$ Associate Professor, Department of Mechanical Engineering, ATME College of Engineering, Mysore, India \\ ${ }^{2}$ Professor, Department of Mechanical Engineering, Govt. College of Engineering, Chamarajanagara, India \\ ${ }^{3}$ Assistant Professor, Department of Mechanical Engineering, ATME College of Engineering, Mysore, India
}

\begin{abstract}
Tic particles were formed in liquid iron solution by the reaction between pure titanium and carbon available in molten $\mathrm{Fe}$-Cr. TiC particles have been precipitated in steels with four different carbon content by in-situ reaction during melting. The influence of titanium, carbon and chromium concentration on the precipitation of $\mathrm{TiC}$ and effect of chromium on TiC was studied. The samples were studied by means of optical microscopy, scanning electron microscopy and X-ray microanalysis. The morphology of the obtained crystals was studied and correlated with carbon and titanium and chromium. It was found that TiC crystallises as primary crystals at $1600^{\circ} \mathrm{C}$ during solidification of the $\mathrm{Fe}$-Cr melt. The obtained crystals were of cubic, rectangle and had maximum of $27.2 \mu \mathrm{m}$ the size and shape of the carbides increases with increasing carbon and titanium in molten Fe-Cr.
\end{abstract}

Keywords: TiC, X-ray, Chromium, Optical Morpology. etc.

\section{INTRODUCTION}

Composites are leading candidate for applications where a good combination of strength and plasticity required. [1] Metal matrix composites [MMCs] are currently one of the focuses of intense research and development worldwide. Although much of the metal matrix composites [MMCs] interest in centred on lighter structural material like $\mathrm{Ti}, \mathrm{mg}$, and aluminium primarily to attain improved strength and stiffness. [2] In recent years metal matrix composites reinforced with ceramic particulates have received considerable attention, For example, Particulate reinforced steel matrix composites have been proposed for use as wear and corrosion resisted parts in the chemical process industry.[3-4] Metal matrix composites dispersed with discontinuous particulates gain a considerable amount of attention as an important engineering material in automotive, aerospace and defence sectors and also to an extent in general engineering because of their improved properties and much lower cost of production.[5]

TiC is one of the most important compounds among transition metal carbides, due to its promising physical properties, such as high melting temperature $\left(3140^{\circ} \mathrm{C}\right)$, a high boiling temperature $\left(4820^{\circ} \mathrm{C}\right)$, high Vickers hardness (25-35 Gpa) high young's modulus ( 410-450 Gpa) low density $\left(4.93 \mathrm{~g}-\mathrm{cm}^{3}\right)$, high flexural strength (240$400 \mathrm{~N} / \mathrm{mm}^{2}$ ), good thermal conductivity $(21 \mathrm{~W} / \mathrm{m} 2 \mathrm{XK})$, high resistance to corrosion and oxidation, high abrasion resistance, high thermal shock resistance. So it is widely used for cutting material, abrasion, anti-wear and aerospace materials.[6-7] $\mathrm{Fe}-\mathrm{Cr}-\mathrm{TiC}$ can be produced by various technologies, some of these technologies include exothermic dispersion(XD), liquid-solid or liquid-liquid reactions, and self-propagation high- temperature synthesis (SHS).Patrick person et al.[8] produced Fe-TiC composites, however, manufacturing of Fe-TiC composites using SHS will encounter large difficulties handling the intrinsic porosity during reaction. S.C.T Jong G.S Wang [9] produced metal matrix composites through Ex-Situ process of fabricating MMCs posses some inherent defects, such as residual micro porosity, uneven distribution of reinforcement, non wetting of the reinforcement and control of matrix reinforcement interface. Scaling up of the process for industrial utilization and processing cost. K.I Parashivamurthy et al [10] produced $\mathrm{Fe}-\mathrm{TiC}$ composites through in-situ technique by reacting $\mathrm{Fe}-\mathrm{C}$ molten alloy with $4,8,12$, and 16 percent of titanium. The evaluation of size, shape and distribution of TiC particles was carried out on all the samples. Kattamis and suganuma [11] have developed Fe-TiC composites by reacting titanium in molten $\mathrm{Fe}-\mathrm{C}$ and mixing of carbides in high carbon steel, and achieved well dispersed carbides in a steel matrix. Y.L. REN, X.L.HAN [12] produced Fe-TiC by in-situ synthesized $10 \% \mathrm{TiC}$ in iron matrix composites. The results shows that $\mathrm{TiC}$ is in two kinds of morphologies, i,e, spherulic and rod-like ones. It is thought that the spherulic $\mathrm{TiC}$ is a proeutectic phase and the rod-like one is a eutectic.

The phase diagram (Figure 1) describes the composites consisting of reinforcements of $\mathrm{TiC}$ in the matrix of ironChromium. In the reaction, initially $\mathrm{TiC}$ nucleates because titanium has an affinity for carbon when compared to iron and chromium, and the distance A-TiC gives the associated free energy, when $\mathrm{TiC}$ precipitates first. The residual driving free energy for the formation of iron carbide and chromium carbide decreases, and it is represented by $\mathrm{B}-\mathrm{CrC}$ and $\mathrm{C}$ $\mathrm{Fe}_{3} \mathrm{C}$. As the driving free energy is reduced by the nucleation of $\mathrm{TiC}$, it may be presumed that the $\mathrm{Fe}_{3} \mathrm{C}$ and $\mathrm{CrC}$ will not nucleate during the composite formation because of kinetic difficulties. As a result, iron carbide and chromium carbide will not appear in the composite casting. 
Therefore, TiC alone will nucleate and stabilize in the matrix. Furthermore, X-ray diffraction analysis confirms the non-precipitation of iron carbide and chromium carbide in the matrix of iron chromium

In the present work, we highlight in-situ techniques were used to produce $\mathrm{Fe}-\mathrm{Cr}-\mathrm{TiC}$ matrix composites. This article gives particular attention to the reaction path and the microstructure of the final product is characterized.

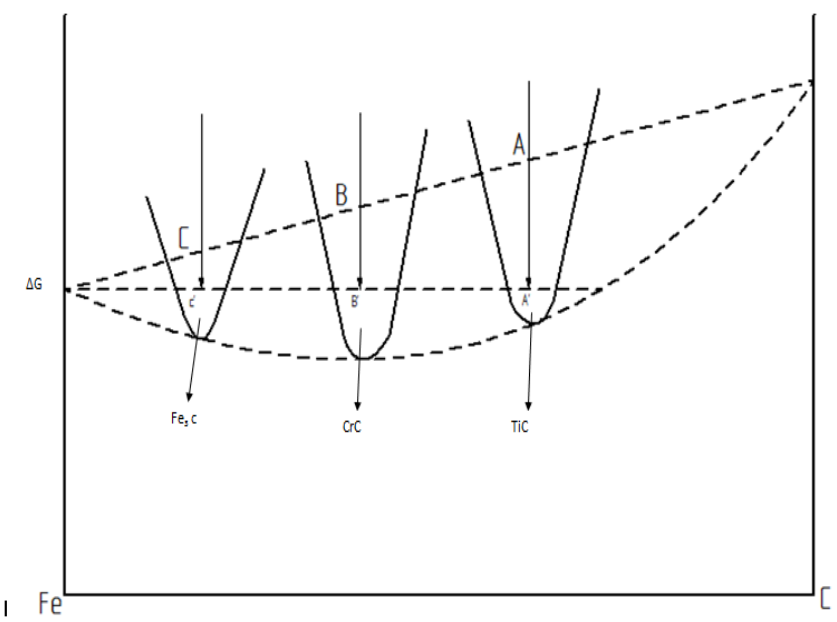

Fig 1: Schematic Free Energy Diagram for Hypothetical Composites

\section{2 .EXPERIMENTAL PROCEDURE}

The induction furnace of $20 \mathrm{~kg}$ capacity was used to melt the alloy. The charge material used was clean steel scrap, Chromium $13 \%$ and petroleum coke. Petroleum coke was used to adjust the carbon content, and 3.5, 7, 10.5 and 14 weight percent of titanium were added respectively. High temperature refractory crucible was used as the reaction container. The crucible was heated via water-cooled copper coils in an induction furnace. The reaction time and temperature are 15 minutes and $1620^{\circ} \mathrm{C}$ respectively. For $\mathrm{TiC}$ formation, a calculated weight of titanium bar was plunged in to the liquid $\mathrm{Fe}-\mathrm{Cr}$ melt to form titanium carbide. After completion of reaction, the power was turned off and melt was poured into sand mould and allowed to solidify. The chemical composition of the base metal was determined using vacuum emission spectrometer, carbon content in the sample were analysed by wet method and composition of the alloy is tabulated as shown in table 1 . The microstructure of composites was examined using optical microscope and scanning electron microscope (SEM). The castings are designated as 1, 2, 3 and 4 for reference based on the volume fraction of $\mathrm{TiC}$ in each of them.
Table 1: Chemical analysis of Fe-Cr-TiC composites in (wt $\%)$

\begin{tabular}{|c|c|c|c|c|c|c|}
\hline Sample no & $\mathbf{C}$ & $\mathrm{Mn}$ & $\mathrm{Ni}$ & $\mathbf{C r}$ & $\mathrm{Ti}$ & $\mathrm{Fe}$ \\
\hline 1 & 0.83 & 0.66 & 0.11 & 13.58 & 0.036 & Balance \\
\hline 2 & 0.85 & 0.52 & 0.94 & 12.58 & 3.99 & Balance \\
\hline 3 & 1.37 & 0.56 & 0.00 & 12.48 & 7.56 & Balance \\
\hline 4 & 1.63 & 0.73 & 0.00 & 12.36 & 10.36 & Balance \\
\hline 5 & 2.14 & 0.36 & 0.00 & 12.24 & 14.51 & Balance \\
\hline
\end{tabular}

\section{MICROSTRUCTURE}

As the chromium is added to iron, amount of carbon solubility in austenite decreases. The carbon content of the eutectoid is diminished and the temperature of the eutectoid reaction is raised. Due to changing temperature effect, chromium reduces the rate of cooling.

Typical microstructure of Fe-Cr-TiC composites is shown in fig 1 and 2 at two magnifications of $100 \mathrm{X}$ and $400 \mathrm{X}$ for sample 2 and 4 . The structure shows the carbide distribution in the matrix with well-defined grain boundary. The size of the carbide increases with increasing carbon with titanium contents.

The size and shape of the carbides is evaluated and are presented in table 2. The morphology showed that the carbide particles below $6 \mu \mathrm{m}$ are drastically reduced and the number with grain size between 20 to $30 \mu \mathrm{m}$ is increased. The size, aspect ratio and volume fraction of $\mathrm{TiC}$ in the $\mathrm{Fe}$ Cr-TiC are presented in table 2.

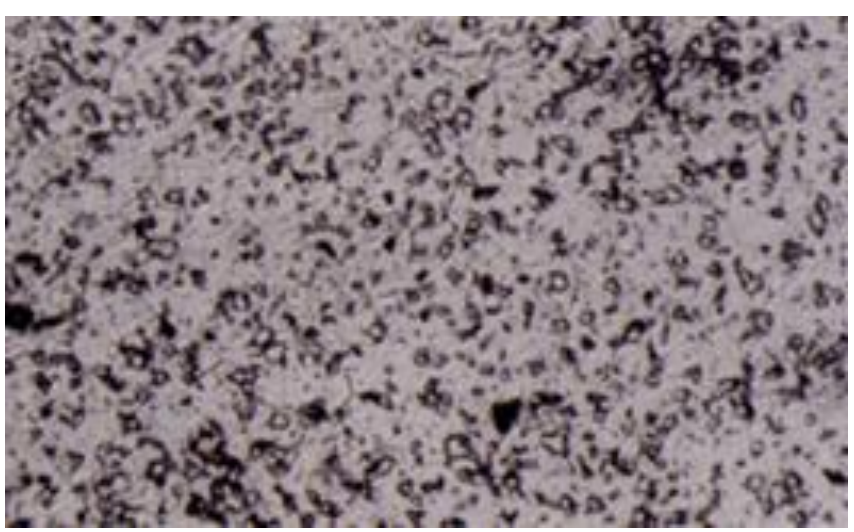

Fig 1: Optical microstructure of sample 2 with lower magnification $(100 \mathrm{X})$ 


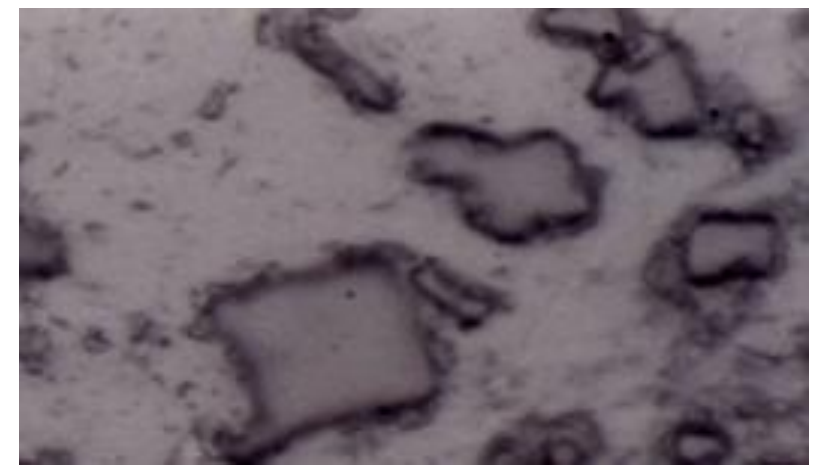

Fig 2: Optical microstructure of sample 2 with higher magnification (400X)

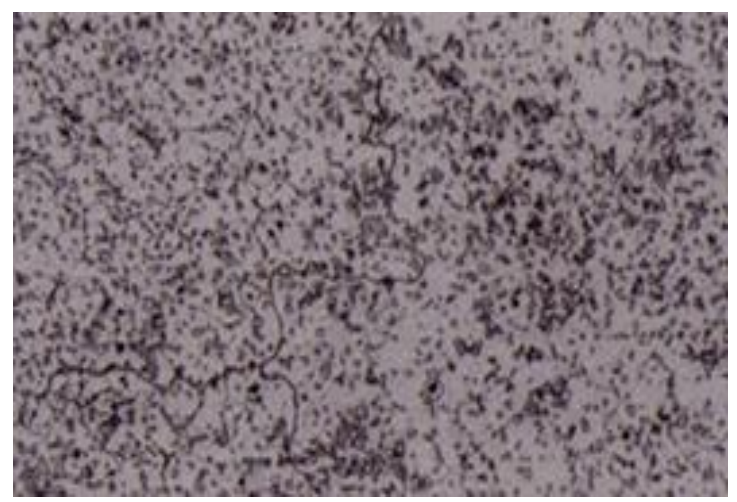

Fig 3: Optical microstructure of sample 4 with lower magnification (100X)

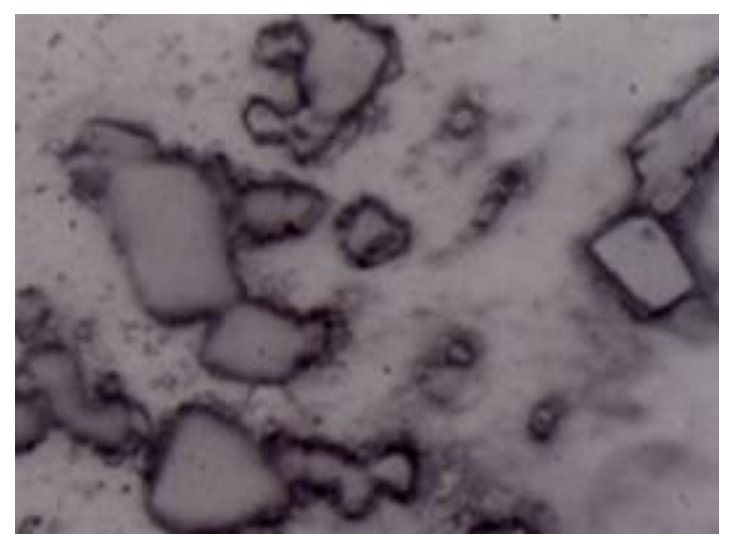

Fig 4: Optical microstructure of sample 4 with higher magnification (400X)

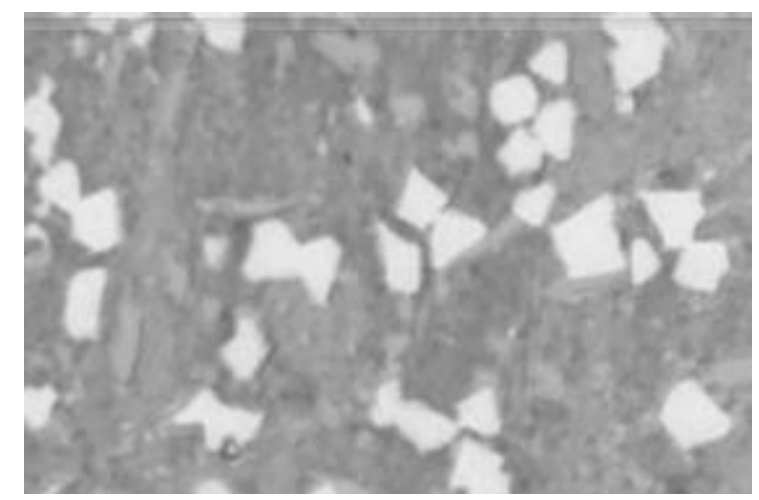

Fig 5: Scanned electron micrograph of Sample 2 with a lower magnification

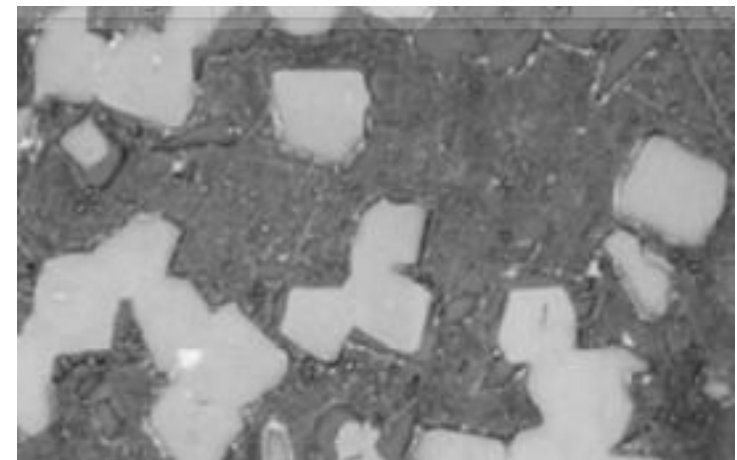

Fig 6: Scanned electron micrograph of sample 4 with a higher magnification

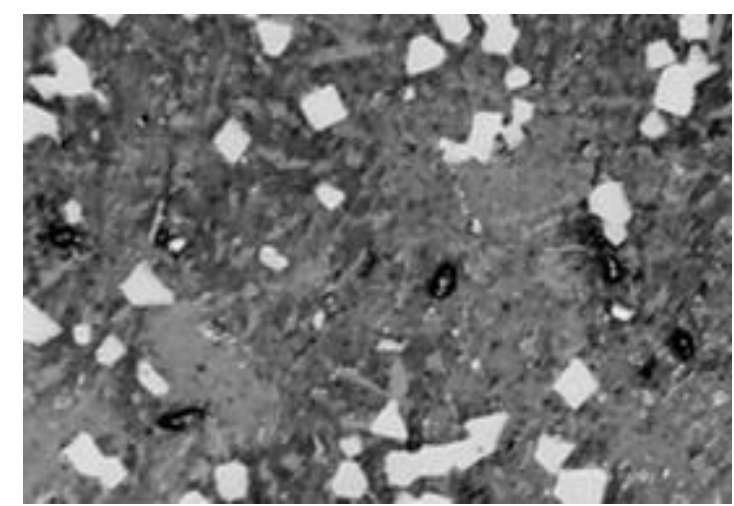

Fig 7: Scanned electron micrograph of Sample 4 with a lower magnification

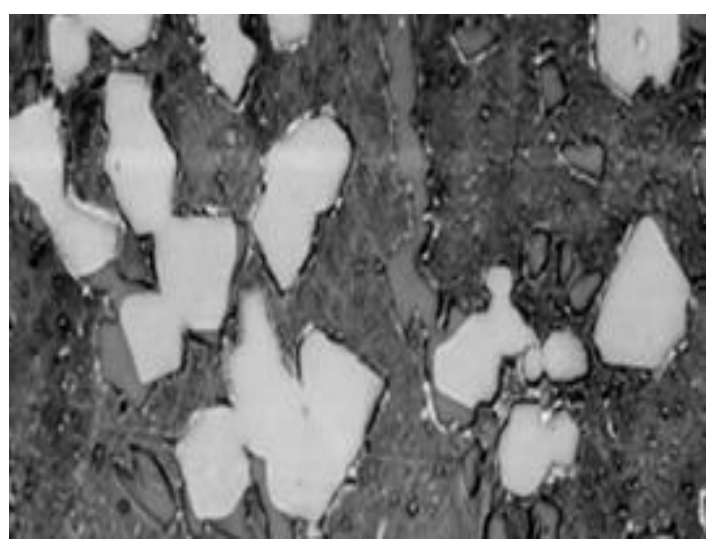

Fig 8: Scanned electron micrograph of sample 4 with a higher magnification

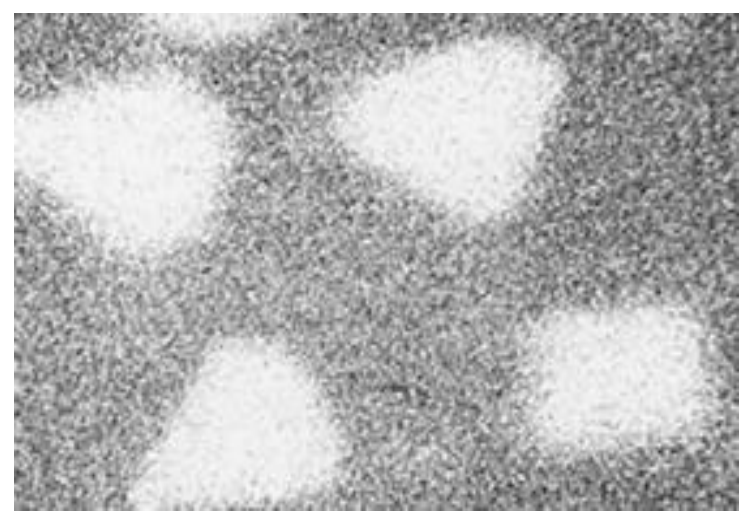

Fig 9: X-ray mapping of Chromium 


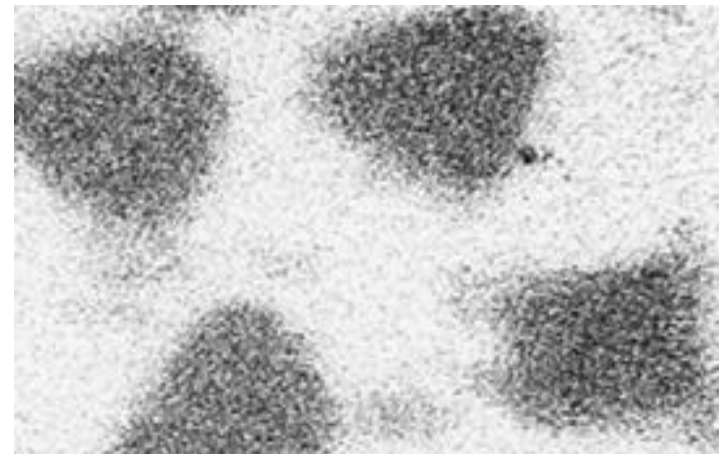

Fig 10: X-ray mapping of Titanium

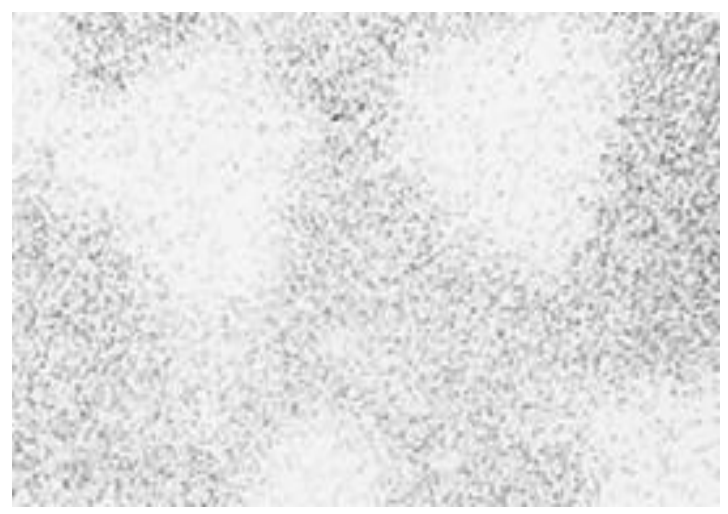

Fig 11: X-ray mapping of iron

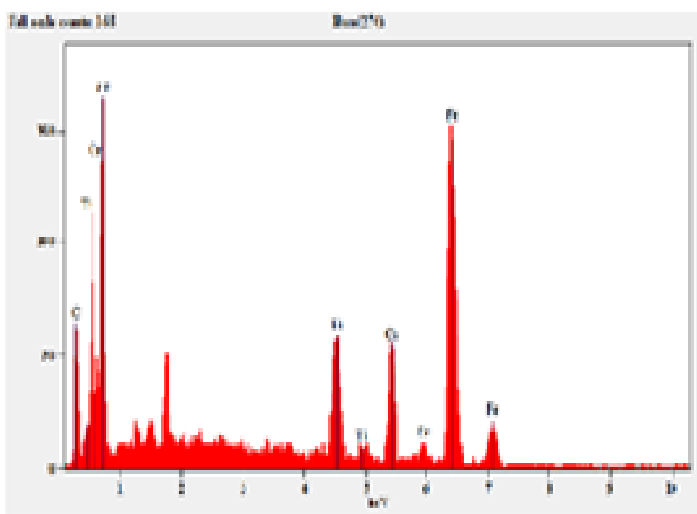

Fig 12: Shows X-ray diffractogram of Sample 4

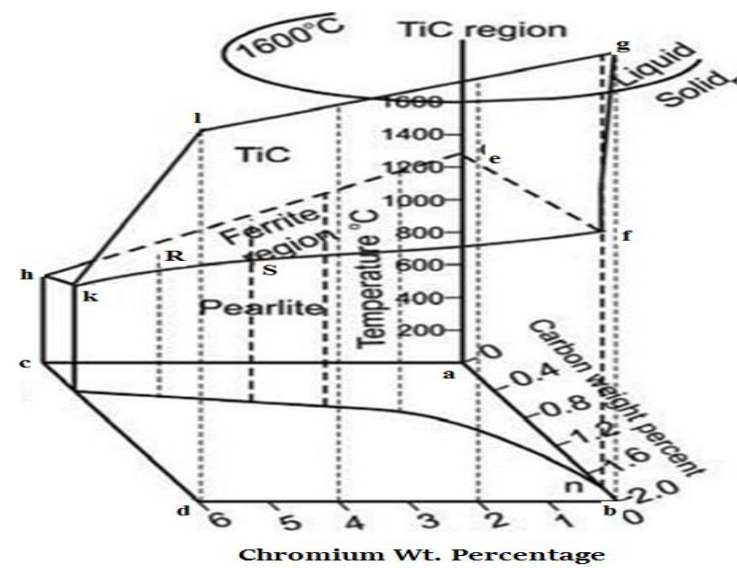

Fig 13: Three-dimensional iron-rich corner of in-situ TiC precipitated $\mathrm{Fe}-\mathrm{Cr}-\mathrm{C}$ phase Diagram
Fig 13 shows a three dimensional drawing of the Tic precipitated in $\mathrm{Fe}-\mathrm{Cr}-\mathrm{C}$ phase diagram. In this diagram, eh represents lowering of $\gamma \rightarrow \alpha$ change in carbon less alloys, fk represents movement of the eutectoid steel, and $\mathrm{nm}$ is the projection $\mathrm{fk}$ on to the base triangle; efhk is the surface on which ferrite begins to form in hypo eutectoid alloys, and fglk indicates which ferrite begins to form in hypo eutectoid alloys, and fglk indicates which $\mathrm{TiC}$ begins to separate in the hypo eutectoid alloys. The TiC crystals nucleate at around $1600^{\circ} \mathrm{C}$ and grow constantly as temperature decreases. At some stage in this process $4 \%$ titanium reacts with $1 \%$ carbon, and the carbon content continuously decreases and and reaches $0.84 \%$ in the residue liquid. As soon as the temperature decreases, the primary $\mathrm{TiC}$ gets enlarged. Further more, at below $1320^{\circ} \mathrm{C}$ ferrite begins form when the austenite is cooled to the appropriate point on the surface fghk. Formation of ferrite precedes and the composition of the austenite moves over this surface until it reaches the eutectoid line bc. At eutectoid temperature the residue austenite is transferred into pearlite.

During the solidification, $\mathrm{TiC}$ crystallize in the matrix, of $\mathrm{Fe}-\mathrm{Cr}$ varies with cooling rate. The $\mathrm{TiC}$ nucleate at $1600^{\circ} \mathrm{C}$ will be in regular shapes like rectangle, square, and the $\mathrm{TiC}$ Precipitate later will be in irregular with varying shapes in the matrix.

\section{CONCLUSION}

Fe-Cr-TiC composites are casted through the in-situ casting route on a small scale by varying $\mathrm{TiC}$ in $\mathrm{Fe}-\mathrm{Cr}$. The additions of chromium to iron-carbon improve hardenability, strength and wear resistance. In Fe-Cr-TiC composites, $\mathrm{TiC}$ is uniformly distributed in the matrix of $\mathrm{Fe}$ Cr. No chromium carbide is precipitated due to the prior formation of $\mathrm{TiC}$ above the liquidus temperature, thus reducing the carbon content of the pro-eutectic phase and subsequent rise in the $\mathrm{M}_{\mathrm{s}}$ Temperature. The TiC crystals often have cubic and rectangular shapes and their maximum size does not exceed $25.5 \mu \mathrm{m}$. Nucleation and retention insitu $\mathrm{TiC}$ is understood by constructing the three dimensional iron-rich corner of $\mathrm{Fe}-\mathrm{Cr}-\mathrm{C}$ phase diagram.

\section{REFERENCES}

[1] Qihong cen, Yehua Jiang, Rong Zhou, Yunhuaxu, and Jianbin wang "Study on in-situ synthesis of TiC partice reinforced iron matrix composites" JMEPEG(2011) 20; 1447-1450.

[2] K. Jayashankar, Animesh mandal, Archana pany, and P.S. Mukherjee. "Synthesis of Fe-TiC in-situ composites by plasma smelting of ilmenite" Material science and manufacturing processes; 26, 13301334,(2011).

[3] S.T. Li, Hui Yuan WANG, S.J.LU, S.L. SUN, D. LI and Q.C. JIANG, Fabrication of Steel Matrix composite locally reinforced with in Situ TiC Particulate via SHS Reaction of (Ti, Fe)-C System during Casting, ISIJ International, Vol 48(2008), No 9, pp, 1293-1298. 
[4] P.Persson, A. Jarfors and S. Savage; J mater, Process technology, 127-131 (2002).

[5] Y. G. ZHAo, S.W. Hu, H.M. SUN and Q.C. JIANG, Fabrication of In situ TiSi (Ti5 Si3, TiSi)/TiC local Reinforced Steel Matrix Composite via Combustion Synthesis, ISIJ International, Vol 49(2009), No 9, pp, 1401-1405.

[6] Youjian Chen, Yongyong Deng, Hong Zhang, Lihua Wang, Jianhua Ma, A novel and simple route to synthesis nanocrystalline Titanium Carbide via the Reaction of Titanium Dioxide and Different Carbon Source, Scientific Research, Materials science and applications,2011,2,1622-1626.

[7] P.Huber, D. Manova, S. Mandl and B. Rauschenbusch, Formation of TiN, TiC and TiCN by Metal plasma Imersion ion implantation and deposition, surface and coatings technology, vol 174175, 2003,pp1243-1247.

[8] P.Persson, A.E.W, Jarfors, and S. Savage, Self Propagating High Temperature Synthesis and liquid phase sintering of $\mathrm{TiC} / \mathrm{Fe}$ composites, Scr. Metall. Mater., 1995,32, p 577-582.

[9] S.C.T Jong, G.S. Wang and Y.W.Mai; Mater, sci. Eng A 358 (2009), 99.

[10] K.I. Parashivamurthy,P.Sampathkumaran, S. Seeethramu, and M.N. Chandrashekharaiah, Microstructure and mechanical properties of In-Situ TiC Dispersed Steel Matrix Composite, Materials science and technology 2007, sept 16-20.

[11] Kattmis T.Z, T Suganuma, Solidification processing and tribological behaviour of particulate TiC-ferrous matrix composite. Mater Sic Engg(1990),A128, 241252.

[12] Y.L.REN, L.QI, L, M; Fu, X.L, HAN, Manufacture characteristics of TiC And (TIW)C iron matrix composites. 